\title{
The failure of the education system to attract girls to formal informatics studies
}

\author{
Joy Teague \\ Valerie Clarke
}

Deakin University

Geelong, Victoria, Australia

\begin{abstract}
Although computers are widely available in the workplace, the school room and the home, statistics indicate that informatics still appeals more to males than to females. Research has shown consistently that boys utilise computers far more than girls in the home, at school and in the community, and receive greater encouragement for doing so. In this paper some historical reasons for this are given, the current situation in Australia is defined, attitudes of Australian schoolgirls to informatics are addressed, some recent educational initiatives described, and suggestions for increasing schoolgirl interest and participation in informatics are made.
\end{abstract}

Keywords: social issues, equity issues, attitudes

\section{INTRODUCTION}

Observations or surveys of enrolments in secondary and tertiary level computing classes, participants in computing games arcades, entrants and winners of computer programming contestants, participants in computer holiday programs, unscheduled extra-curricula users of school computing 
facilities, and owners and users of home computers consistently indicate that males have a greater interest in, and greater access to, computers than do females [1]. However, studies of abilities show that there are minimal gender differences in general ability, computing ability or computing achievement, and that, when girls are required to enrol in compulsory courses in informatics, they perform as well as their male colleagues despite their more limited experience on entry to these courses [2]. Thus gender differences in interests and participation in informatics seem to arise from the way in which informatics is introduced into schools [3], a process which facilitates the development of gender differences in interest in informatics and beliefs about the gender appropriateness of informatics studies and careers.

\section{An historical perspective}

It is interesting to note that in the early days of computers these gender differences did not exist. Two women who were well known for their very early involvement with computers were Lady Ada Lovelace and Admiral Grace Hopper. In the very early days of computers women were employed as programmers as most young men were away at war. It has been suggested that women were preferred for programming work because they had the necessary "patience" and "attention to detail" for what was regarded as an essentially low-level clerical job [4].

In the 1960s entry into informatics occupations was by way of "aptitude tests", generally a type of intelligence test. As women and men, from arts or science backgrounds, are equally likely to score well on such tests, women were as likely as men to be employed. Women working in informatics in the early 1960 's recollect that the field was not viewed as being male dominated at that time. It was the developments which occurred over the next twenty years which have established computers as being primarily the province of men and boys. These developments occurred in two periods: the early 1970's and the mid-1980's.

Around 1970 computer science was established as a university discipline located in science and engineering faculties. As the normal prerequisites for science and engineering courses, science and mathematics, have traditionally low female enrolments in most Western countries, relatively few women enrolled in computer science courses. These courses became the standard entry requirement for informatics occupations, and the profession became stereotyped as a male occupation. Consistent with social role theory, girls perceived the gender imbalance in informatics courses and occupations and made the incorrect assumptions that existing jobs reflected existing abilities and attitudes [5], or that men 
had the interests, attitudes and abilities required for courses in maths, science and computing and that women lacked these abilities, interests and attitudes. Such perceptions influenced their beliefs of the suitability of informatics, not only for men and women in general, but as subjects and careers they should consider for themselves.

Around 1980 mini- and micro-computers became affordable and widely available. These computers were introduced initially into schools by mathematics and science teachers, with computing classes reflecting teachers' interests in mathematics and science. Software was limited. Most computers were purchased with 'on-board BASIC', and users were expected to write their own programs. Computer use required skills with complicated operating systems and editors, which limited computer usage to those who had the time and the interest to spend learning these systems. For societal and cultural reasons, these users were more likely to be male than female $[3,6]$. At about this time, tertiary level female computer science enrolments in Britain and the United States began to drop, and declined steadily throughout the 1980 s $[7,8]$.

\section{Hardware and software developments}

The problems arising from a shortage of appropriate software have been resolved. Today there is an extensive and diverse range of software available, enabling computers to be used with little or no formal training. The majority of programs are menu driven and contain explicit directions enabling them to be used with only an hour or two of training in computer use. Costs of computers have declined dramatically, placing them within the reach of a greater section of the population. Most schools have at least one well equipped computing laboratory. Many homes have one or more computers. Schoolchildren know that most members of the workforce use computers in their jobs.

What has been the effect of this hardware and software revolution on schools? There has been a realisation that computers can be used across the curriculum. Word processing, spreadsheets, and graphics improve the quality of most assignments. The teaching of humanities subjects, such as history and economics, can be enhanced with database packages. Specialised teaching packages are available in most disciplines. The world of multimedia is developing rapidly.

At informatics education conferences teachers and developers discuss innovative and exciting applications of computers across the curriculum. Attending conferences, such as the annual United States National Educational Computing Conference or the Australian Educational Computing Conference, makes one aware of the diverse range of available 


\section{Integrating information technology into education}

software, the broad penetration of informatics into the school curriculum, and the remarkable achievements of dedicated and enthusiastic teachers. With the hardware and software available today, informatics should be available to all students in all disciplines in all schools. However, this does not seem to be the case.

\section{The current situation in most Australian schools}

The reality of computer use in Australian schools was clearly explained by a regional school computing co-ordinator, who described the situation in his own area, but indicated that this was relatively typical of most regions. This co-ordinator is responsible for providing advice, information and short courses to teachers in more than one hundred primary and secondary schools spread over some twenty thousand square kilometres. Very few schools (none in his region) have sufficient resources to allocate one computer to each student or pair of students, so computers are placed in laboratories with selected classes being scheduled in these laboratories. The prohibitive cost of software packages limits many schools to utility packages incorporating word processing, databases, spreadsheets and graphics. Specialised packages for individual subjects are rarely available within the school.

Although teachers have been given opportunities to develop their skills, many are still not comfortable with computers, particularly as many of their students may know more than they do. New initiatives in teaching require time and enthusiasm to develop. How many teachers in any country have sufficient time to devote to becoming familiar with computer software and developing applications? Some will make time, most will not.

It was the view of this regional co-ordinator that, too frequently, a school's "computer guru" hinders rather than helps his or her colleagues' acquisition of computing skills, for example, by not passing on information about courses which are being offered and which would be relevant. In many schools, informatics in the classroom is restricted to learning introductory keyboarding skills, word-processing, and an introduction to selected general applications, while mathematics and computer science classes retain traditional computer science with a strongly mathematical orientation.

Many of the views expressed by this typical co-ordinator were echoed by participants at the educational informatics conferences. Most participating teachers, irrespective of whether they are from the United States of America or Australia, express their frustrations which are created as a result of sitting through exciting multi-media presentations of specific 
curricula components, knowing that these packages are beyond the financial resources of their individual schools. Many comment that their schools contain too high a proportion of teachers with minimal interest in informatics and little recognition of the need for their students to become involved with this developing technology.

\section{Attitudes of schoolgirls towards informatics}

Given that most school have at least one computer laboratory, how successful are school computing classes? We attempted to answer this question by asking schoolgirls. In a qualitative study of secondary girls' attitudes towards informatics, thirty-two girls, aged 13 to 17 years, were interviewed. Girls from four schools, encompassing all combinations of public, private, single-sex and co-educational schools were included. The girls to be interviewed were selected by the schools; the contact teacher was asked to identify girls who had the ability to study informatics at higher levels, but who had not necessarily displayed an interest in the topic.

The girls were asked about their career aspirations, whether they enjoyed their school informatics studies, whether they used a computer at home, and what they thought about careers in informatics. The motivation for the study arose from an earlier series of interviews which indicated that the perceptions of computers and computing held by university computer science and informatics students were markedly different from those of women working in the field [9].

When asked about their informatics studies at school, the schoolgirls typically described their classes, and informatics in general, as 'boring', and not an area to study voluntarily. Their views apparently related to their experiences in learning keyboarding and basic computing skills in a formal classroom situation. In none of these four schools had teachers managed to make informatics classes enjoyable and motivating for the majority of female students. It appeared that students were taught using standard class exercises. While this approach is used in many subjects, it is clearly turning girls away from formal informatics studies. The only three students who mentioned specifically that they had enjoyed their informatics studies were older students who reported using a variety of application packages in the later years of their schooling.

When asked about their home use of computers the girls who had access to a computer at home become enthusiastic, describing the advantages of using a computer to complete assignments. Word processing was the main application of home computers, however, graphics packages, mathematical work and spreadsheets were being used. 


\section{Integrating information technology into education}

The girls interviewed appeared not to relate what they did at home to the formal informatics instruction of the classroom, and did not consider their home computer use to be informatics.

The problem appears to be one of relevance. These girls enjoy using computers at home to achieve their own objectives, but may not enjoy formal tuition in informatics when the class objectives are not consistent with their own immediate goals. They do not see any similarity between what they do at school and what they do at home.

In contrast to the bleak picture conjured up by the interviews, one local high school has its computer laboratories filled with girls at lunch time. The girls, and a few boys, use the computers to prepare high quality assignment submissions, where as, a decade ago, it was game playing boys who filled the room at lunch time. Enthusiastic schoolgirl users such as these can be found in schools world-wide where computers can be used to enhance the quality and presentation of projects which girls find interesting and relevant [10].

The schoolgirls we interviewed did not see informatics as an attractive career option, believing it to involve working in isolation and sitting at a screen all day, although they admit to having little knowledge of the careers available. In contrast, women using informatics in the workplace describe their work as challenging, varied and requiring constant interaction with people. In fact, the women working in informatics identify the very same job characteristics which the schoolgirls were seeking in an ideal job. It seems to be lack of knowledge about the real world of informatics, rather than the true nature of informatics which is turning girls away.

\section{Victorian certificate of education}

A few years ago the Victorian government introduced the new Victorian Certificate of Education (VCE) which consists of 24 units of study completed over the final two years of secondary education. The units completed in the second year of the VCE are assessed using Common Assessment Tasks (CATs), of which approximately one-third are examinations with the remaining tasks being essays or projects completed over a number of weeks. Students are required to submit plans and drafts of their work prior to the final submission. The intention is to encourage the development of skills which are needed in the workplace. Most students have discovered that computers are fantastic tools for completing these tasks as they can present revised drafts without re-writing. Additionally, computers have spelling checkers and word counters, and they can be used to produce graphs and diagrams as well as to analyse 
data. Some students have their own private computers while others rely on the school computing facilities. Although this was not a stated intention of the structure of the VCE, the increased recognition of the role of computers has certainly resulted from the changed curriculum and assessment demands. Students have discovered that computers are very useful tools that enable them to produce better quality work with considerably less effort than is possible without these facilities. Even without the VCE, schools could learn from this experience and devise more assessment tasks which would benefit from the development of skills in informatics.

\section{The importance of diverse experiences}

While it is not possible for all students to have their own personal computer, it is possible for teachers to maximise the limited access time available by ensuring that their students have a broad range of informatics experiences. The importance of diversity was demonstrated in a recent study of approximately 200 secondary girls drawn from both single-sex and co-educational schools. Jones and Clarke [11] found that the girls in the single-sex schools had more positive attitudes towards computers than did the girls in the co-educational schools, such differences being independent of whether the schools were government or non-government schools. However, a more detailed analysis of the data showed that the girls' attitudes were influenced by the diversity of their experience with computers, rather than, as often implied in previous research, the sheer amount of computing experience. It seems that girls in single-sex classes were mastering a particular computing application, then approaching the teacher to be allowed to use a different application. In co-educational classes girls were mastering an application and continuing to use it, as they felt comfortable with that application and were reluctant to compete with the boys for either the teacher's attention or the opportunity to use a different application. The data clearly indicate the importance of using time in informatics classes to provide students, both girls and boys, with experience with a wide range of applications to enable them to develop an appreciation of the uses of computers and more positive attitudes towards using them.

\section{CONCLUSION AND RECOMMENDATIONS}

Whilst schools have been successful in providing students with opportunities to use computers, they have been less successful in 


\section{Integrating information technology into education}

providing those opportunities across the curriculum, and apparently have failed to stimulate interest in the exciting world of informatics, particularly among female students. This could be addressed in the following ways.

Resources. The resource issue needs to be addressed, whether by the provision of additional resources or the development of shared computing laboratories with shared software. Increased sharing is possible. At the upper secondary level in Victoria groups of secondary schools are re-organising into middle school campuses teaching years 7 to 10 and secondary colleges campuses teaching years 11 and 12. By sharing facilities across a large multi-campus organisation rather than working as separate schools, there is a greater potential for sharing hardware and software.

Class time. In the limited time available to teachers using computing laboratories, it is important to provide students with a variety of different informatics experiences. Rather than focussing on one application and thoroughly mastering its use, teachers may be better advised to allow students to have an introduction to a variety of different computer applications.

Relevance. Girls in particular need to see the relevance of learning to use a particular application. By introducing a range of applications through the development of a group project, students can not only see the need to develop skills in informatics, but can also learn to work as members of a team, developing the interpersonal skills so essential to most jobs, and especially to jobs in informatics.

Not only informatics. The study of informatics should not be limited to informatics classes. Students should been encouraged to use their informatics skills to collect, analyse, organise and present information across all areas of the curriculum.

Image. The common, but inaccurate image of careers in informatics as boring and socially isolating needs to be replaced with a more accurate image indicating the extent to which these workers enjoy the challenge, variety, problem-solving, people-oriented nature of their jobs.

Girls' informal use of computers suggests that informatics is again becoming gender neutral, and that schools must consider means of stimulating interest in formal informatics classes. 


\section{REFERENCES}

1. Clarke, V.A. (1992) Strategies for involving girls in computer science. in In Search of Gender Free Paradigms for Computer Science Education, C.D. Martin and E. Murchie-Beyma, (eds.). NECC Monograph: Eugene, Oregan. 71-86.

2. Clarke, V.A. and S.M. Chambers. (1989) Gender-based factors in computing enrolments and achievements: Evidence from a study of tertiary students. Journal of Educational Computing Research. 5, 409-429.

3. Culley, L. (1988) Girls, boys and computers. Educational Studies, 14 (1), 3-8.

4. Jones, S. (1991) Why do we want to see more women in computing?, in Women into Computing, G. Lovegrove and B. Segal, Editors. Springer-Verlag: London. 59-65.

5. Eagly, A.H. (1987) Sex differences in social behavior: A social-role interpretation. Hillsdale, NJ: Lawrence Williams Associates.

6. Clarke, V.A. (1990) Sex differences in computing participation: concerns, extent, reasons and strategies. Australian Journal of Education, 34 (1) 54-68.

7. Lovegrove, G. and Hall, W. (1991) Where are the girls now? in Women into Computing, Lovegrove, G. and Segal, B. (eds.) SpringerVerlag: London. 33-45.

8. U.S. Department of Education. (1993) Office of Educational Research and Improvement, National Center for Educational Statistics, Washington, D.C.

9. Teague, G.J. and Clarke, V.A. (1991) Fiction and fact: Students' and professionals' perceptions of women in computer science, in Women, Work and Computerization: Understanding and Overcoming Bias in Work and Education, I.V. Ericksson, B.A. Kitchenham, and K.G. Tijdens, (eds.). North-Holland: Amsterdam. 363-375.

10. Yewlett, H. (1992) Everyone does information technology in Ystalyfera! in: the proceedings of Women into Computing. Teaching Computing: Content and Methods. Keele University, Staffordshire: p. 215-221.

11. Jones, T. and Clarke, V.A. (1993) Girls and computers: An assessment of the advantage of single-sex settings. Presentation at Networking in the 90's. The 2nd Women in Computing Conference, Melbourne. 

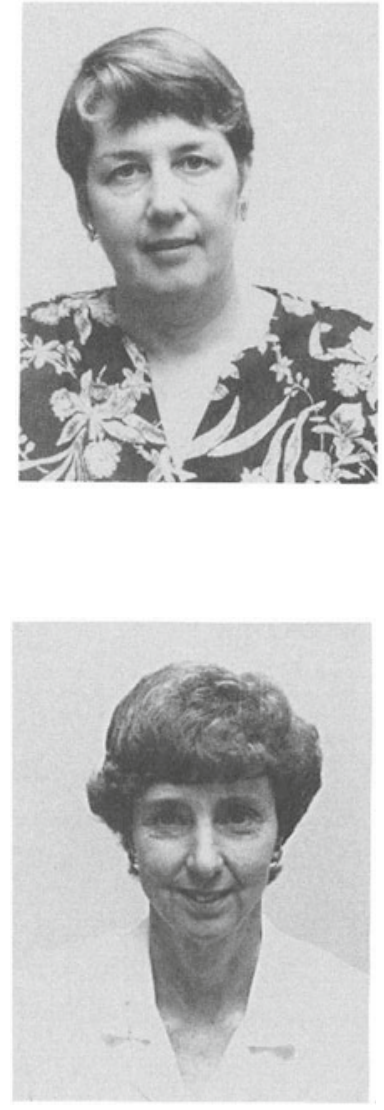

Joy Teague completed her high school education in 1964 and started work in a bank. Eight years later, after completing a part-time B Sc, embarked on an academic career at the Gordon Institute of Technology, and, in 1977, transferred to Deakin University. Currently a Senior Lecturer with the School of Computing and Mathematics at Deakin, she is enrolled in her fourth part-time degree programme, studying for a $\mathrm{PhD}$. Primary research interest is gender related perceptions of computing careers.

Val Clarke completed her secondary education at a private girls' school before majoring in psychology in Arts at Melbourne University where she was awarded a BA (Hons) and an MA. She lectured in Humanities at the Gordon Institute before leaving to become a full-time mother on the birth of the first of her two daughters. She returned to work at Deakin University in 1979 as a Senior Tutor. After many years of teaching and research and completing a $\mathrm{PhD}$ at Deakin, she is now a Senior Lecturer. Val's major research area is gender issues, with a special emphasis on the increased participation of women in mathematics, science and technology. 